\title{
Saberes e a Ciência Ecológica: emergências da complexidade
}

\author{
Saberes y la Ciencia Ecológica: emergencias de la complejidad \\ Knowledge and Ecological Science: emergencies of complexity
}

\author{
Sabrina Amaral Pereira ${ }^{1}$ \\ Gionara Tauchen ${ }^{2}$
}

\begin{abstract}
Resumo
A ciência ecológica é uma ciência/consciência planetária, pois envolve múltiplas dimensões da vida e suas relações com o mundo. Este estudo de natureza hermenêutica, objetiva compreender a constituição da ciência ecológica, expressando, a partir do pensamento complexo, suas emergências. O estudo decorre dos seguintes questionamos: Quais as consequências/influências dos processos históricos da ecologia enquanto campo da ciência? Quais seus princípios organizadores na contemporaneidade? Diante das considerações históricas, percebemos a ecologia constituída pela contribuição de múltiplas áreas, as quais contribuíram com diferentes momentos e intenções: descritiva, numérica, unidade na diversidade, princípios organizadores. Logo, compreendemos que cada acontecimento/conhecimento integra, produz e é produzido a cada momento histórico, formando uma espiral recursivamente autoalimentada. No entanto, para pensarmos em uma ecologia emergente, precisamos ampliar esta espiral e observar um emaranhado de múltiplos e infinitos plurianéis em movimento, no qual todos os níveis de organização estão superpostos, interligados, contribuindo para a autoeco-organização. Assim, vemos emergir uma ciência integradora que considera o seu objeto de estudo mergulhado no contexto, descrevendo-o e concebendo-o nas inter-retroações com os mais diferentes componentes, os quais se relacionam com conceitos das diversas disciplinas clássicas, complexificando-os.
\end{abstract}

Palavras-Chave: Ciência integradora; Concepções históricas; Ecologia emergente.

\section{Resumen}

La ciencia ecológica es una ciencia / conciencia planetaria, pues implica múltiples dimensiones de la vida y sus relaciones con el mundo. Este estudio de naturaleza hermenéutica, objetiva comprender la constitución de la ciencia ecológica, expresando, a partir del pensamiento complejo, sus emergencias. El estudio se deriva de los siguientes cuestionamos: ¿Cuáles son las consecuencias / influencias de los procesos históricos de la ecología como campo de la ciencia? ¿Cuáles son sus principios organizadores en la contemporaneidad? Ante las consideraciones históricas, percibimos la ecología constituida por la contribución de múltiples áreas, las cuales contribuyeron con diferentes momentos e intenciones: descriptiva, numérica, unidad en la diversidad, principios organizadores. Luego, comprendemos que cada acontecimiento / conocimiento integra, produce y se produce en cada momento histórico, formando una espiral recursivamente autoalimentada. Sin embargo, para pensar en una ecología emergente, necesitamos ampliar esta espiral y observar un enmarañado de múltiples e infinitos plurianeles en movimiento, en el cual todos los niveles de organización están superpuestos, interconectados, contribuyendo a la auto-organización. Así, vemos emerger una ciencia integradora que considera su objeto de estudio sumido en el contexto, describiendo y concebiéndolo en las interrelaciones con los más diferentes componentes, los cuales se relacionan con conceptos de las diversas disciplinas clásicas, completándolos.

Palabras claves: Ciencia integradora; Concepciones históricas; Ecología emergente.

\section{Abstract}

\footnotetext{
1 Doutoranda em Educação em Ciências; Universidade Federal do Rio Grande; Rio Grande, RS, Brasil; sabri.pereira@hotmail.com

${ }^{2}$ Doutora em Educação; Professora Adjunta da Universidade Federal do Rio Grande - FURG; Diretora de PósGraduação/Pró-Reitoria de Pesquisa e Pós-Graduação; giotauchen@gmail.com
} 
Ecological science is a planetary science / consciousness because it involves multiple dimensions of life and its relationships with the world. This study of hermeneutical nature, aims to understand the constitution of ecological science, expressing, from the complex thinking, its emergencies. The study follows from the following questions: What are the consequences / influences of the historical processes of ecology as a field of science? What are its organizing principles in contemporary times? Considering the historical considerations, we perceive the ecology constituted by the contribution of multiple areas, which contributed with different moments and intentions: descriptive, numerical, unity in diversity, organizing principles. Therefore, we understand that each event / knowledge integrates, produces and is produced at each historical moment, forming a recursively self-powered spiral. However, to think of an emerging ecology, we need to expand this spiral and observe a tangle of multiplicity and infinite plurianéis in movement, in which all levels of organization are superimposed, interconnected, contributing to self-organization. Thus, we see an integrative science emerge that considers its object of study plunged into the context, describing it and conceiving it in the interreactions with the most different components, which relate to concepts of the various classical disciplines, and to complex them.

Keywords: Integrative science; Historical conceptions; Emerging ecology.

\section{Considerações iniciais}

O "pensamento ecológico" remonta o início da humanidade, em que os primitivos começaram a explorar o ambiente natural a fim de atender as suas necessidades, pois precisavam conhecê-lo. Por isso, Acot (1990) nos diz que para estabelecer uma história da ciência ecologia necessitamos, primeiramente, refletir e compreender as continuidades, as rupturas e as tensões entre o "saber ecológico" e a "ciência da ecologia". Para o autor, este primeiro está mais relacionado a correlações observadas, de maneira bastante empírica e pontual; já nos saberes de uma proposição de ciência da ecologia, as observações são portadoras de generalizações teóricas, propondo leis de estruturação e de funcionamento.

Neste sentido, os filósofos gregos (Aristóteles, Teofrasto e Hipócrates), em seus textos, já faziam referências às questões ecológicas (ODUM, 2001). Para alguns autores (BODENHEIMER, 1954; EGERTON, 1977), os escritos de Aristóteles, por exemplo, em "História dos Animais", seriam, pelo menos, precursores de uma ciência ecológica. No entanto, Acot (1990) alerta que a filiação epistemológica entre História dos Animais e a ecologia moderna é ilegítima, uma vez que a primeira persegue fins e funciona num quadro de causalidade portadora de uma intencionalidade sábia, ao contrário da ciência ocidental moderna, que porta e expressa uma concepção mecanicista e materialista do mundo.

Neste sentido, Morin (2015b) esclarece que o pensamento de nossos ancestrais era unidual, ou seja, suas estratégias de conhecimento e ação eram, ao mesmo tempo, empíricas/técnicas/racionais e simbólicas/mitológicas/mágicas, muito integradas com o pensamento religioso. Também, nos últimos desenvolvimentos da história, se operou uma ruptura entre a ciência e a religião, levando a razão e a ciência à pretensão de reger e guiar o conhecimento da humanidade. Portanto, há uma diferença entre a natureza dos conhecimentos produzidos, o que leva a produzir divergências entre os pesquisadores sobre o início da 
ecologia enquanto ciência. Neste sentido, questionamos: Quais as consequências/influências dos processos históricos da ecologia enquanto campo da ciência? Quais os princípios organizadores da ecologia na contemporaneidade?

A partir destas considerações, organizamos este estudo teórico, de natureza hermenêutica, objetivando compreender a constituição da ciência ecológica, expressando, também, a partir do pensamento complexo, suas emergências.

\section{Ecologia: Historicidade e concepções}

Na história da Ecologia, destaca-se um "precursor" da ciência ecológica, Carl Von Linne (séc. XVIII), naturalista preocupado com a teologia, médico e botânico, que se dedicou a estudar espécies botânicas e ficou conhecido por ser o criador da nomenclatura binomial e da classificação científica, sendo, assim, considerado o "pai da taxonomia moderna" (PRESTES et al., 2009). A questão ecológica ligada a Lineu - Economia da Natureza - está na constatação da "existência de um sistema da Natureza que preside às inter-relações específicas (fins intermediários e equilíbrio) e, que como teólogo designa uma origem e uma finalidade divinas" (ACOT, 1990, p. 5). Segundo Acot (1990), apesar de as formulações linelianas influenciarem algumas concepções modernas por volta do fim do século, como, por exemplo, o conceito de comunidades, sua problemática ainda não é ecológica, pois estão pautadas no providencialismo e no finalismo.

Ainda no século XVIII, devido às numerosas expedições marítimas pré-coloniais, muitos botânicos, como Lineu, embarcaram nestas viagens, o que resultou na ampliação do conhecimento das espécies vegetais de diferentes lugares, embora ainda bastante descritiva (ACOT, 1990). Com isso, foram percebidas relações entre as vegetações e as características climáticas, as quais Alexandre Humboldt, em 1805, denomina de "geografia das plantas". Diante disso, os geobotânicos da época começaram a se dedicar ao estudo destas relações, produzindo diversos conceitos como "forma de crescimento", "associações vegetais", os quais exercerão forte influência nos conceitos da ecologia. Aqui, podemos perceber, claramente, que depois de um conhecimento considerável da flora terrestre (partes) foi possível pensar e definir relações entre as características do ambiente (neste caso, o clima), estabelecer generalizações (todo) e complexificar os conhecimentos (relação entre parte e todo) para entender melhor a estrutura desta comunidade, construindo, assim, uma abordagem ecológica na medida em que estabelece estas inter-relações.

No entanto, o termo ecologia teve a sua origem somente em 1866, com o biólogo alemão Ernest Haeckel, seguidor dos ensinamentos de Charles Darwin, que desenvolveu a 
proposta deste termo definindo ecologia como "o estudo do ambiente natural, inclusive das relações dos organismos entre si e com seus arredores". Dentre as variações de definição propostas por ele, Acot (1990) ressalta claramente que o seu conceito constitui-se no quadro científico e ideológico da economia da natureza, dos equilíbrios naturais e da adaptação dos seres vivos às suas "condições de existência". Uma questão importante a ser refletida é o fato de que os estudos e definições de Haeckel possuem forte influência e fazem referências explícitas ao darwinismo, o que não se aplica às correntes pré-ecológicas no século XIX, a biogeografia vegetal. Isso pode ser verificado nos trabalhos de Humboldt sobre a geografia das plantas, considerados como um pensamento pré-ecológico porque se referia às relações entre ser vivo e meio ambiente, em que observamos que este se afasta da noção de espécie (parte), o que vai de encontro às ideias de Darwin, que, apesar de não ter uma intenção classificatória, contempla suas pesquisas com foco na evolução das espécies (ACOT, 1990). Assim, "Haeckel batiza uma disciplina ainda não constituída, mas cujo objeto (as relações ser vivo e meio externo) já está trabalhado" (ACOT, 1990, p. 31).

Desta forma, somente em 1895, o termo "ecologia" apareceu em um trabalho de geobotânica por Eugen Warming, considerado o fundador da ecologia como um ramo original da biologia. Foi com Warming que as questões da geobotânica foram centradas em um estudo sistemático, levando em consideração a "economia das plantas", suas exigências em face ao meio ambiente, seus modos de adaptação às condições exteriores no plano de suas estruturas, suas fisionomias e suas formas de vegetação (ACOT, 1990). Portanto, Acot (1990) nos afirma que a obra de Warming contribuiu para estimular a criação de organismos de pesquisas centrados na ecologia, depois de unidades de ensino desta nova disciplina.

Ao longo do final do século XIX e início do XX, muitos pesquisadores desenvolveram trabalhos com uma grande importância para a ecologia. Temos como exemplo Schimper que abordou os problemas ecológicos sob o ângulo da fisiologia vegetal, e Clements e Cowles (entre 1898 e 1907) que trabalharam com o que, hoje, chamamos de botânica das sucessões. É importante salientar as potencialidades destes trabalhos enquanto Warming e Schimper edificaram uma "ecologia estática", ou seja, sem considerar o desenvolvimento das comunidades ao longo do tempo. Enquanto isso, os ecólogos americanos Clements e Cowles lançaram bases para uma "ecologia dinâmica", considerando a sucessão ecológica das comunidades vegetais, e, ao mesmo tempo, as elaborações teóricas eram conduzidas simultaneamente com a prática da pesquisa de campo (ACOT, 1990).

Neste contexto, Frederic Edward Clements desempenhou um importante papel no plano teórico, introduzindo metodologias, técnicas e instrumentos de pesquisa, e, pela 
primeira vez na história da ecologia, produzindo uma obra pedagógica, ou seja, encarnando a dinâmica interna da ecologia de seu período (ACOT, 1990). Cabe lembrarmos que, na época, a ciência ocidental estava em extraordinário progresso, desvinculando-se da questão religiosa e assumindo uma "base racional, experimental, quantificada e positiva na busca de leis gerais e universais reguladoras dos fenômenos naturais e sociais” (ROSA, 2012 p. 29). Assim, Clements dedicou-se à pesquisa da ecologia das sucessões, contribuindo com a criação de conceitos e processos essenciais para a ecologia, como "homeostasia dos ecossistemas" e plantas como indicadores de comportamento e características do ambiente, e/ou de outras plantas e animais que vivem no mesmo local.

Como podemos observar, as origens da ecologia remontam, de modo geral, estudos em ecologia vegetal. Segundo Acot (1990), em um olhar rápido, pensamos que houve, no século XIX, certo desenvolvimento paralelo entre ecologia vegetal e animal, uma vez que Humboldt já evocava a "geografia dos animais" (ACOT, 1990). No entanto, Acot (1990) nos alerta que se olharmos mais de perto os trabalhos da época, a ecologia animal está consideravelmente atrasada em relação à geobotânica. Assim, muitos zoólogos da época acabam incorporando os conceitos e métodos da ecologia das sucessões vegetais. Neste sentido, podemos destacar Charles Chase Adams (1905) e V. E. Shelford (1907) com os estudos das sucessões bióticas. A partir de 1907, começaram a surgir inúmeros trabalhos relacionados às comunidades bióticas que contribuíram para o estabelecimento de outros conceitos ecológicos, como a noção de "equivalência ecológica", "nicho ecológico", com Charles Elton, e, em 1916, Clements introduziu o conceito de "bioma" para designar a unidade biogeográfica que constituem uma formação vegetal e animal que lhe corresponde.

Dessa forma, o progresso dessas concepções conduziu a uma ecologia voltada para o estudo das comunidades, acarretando, assim, ainda muitos questionamentos sobre os mecanismos internos de inter-relações, regulação e equilíbrio destas comunidades. Cabe ressaltar que neste período, devido ao avanço das pesquisas e descobertas e à possibilidade de realizar previsões, as potencialidades econômicas da ecologia animal e vegetal começaram a gerar interesse de pesquisadores. No entanto, a ecologia ainda não possuía peso econômico, pois esta ainda era muito descritiva e carecia de conhecimentos, como os mecanismos de biocenoses (ACOT, 1990).

Este conceito de biocenose foi proposto por Möbius, em 1877, definindo como "uma comunidade na qual a soma das espécies e dos indivíduos, sendo mutuamente limitada e selecionada pelas condições médias de vida exteriores, continuou, via reprodução, a ocupar um território dado". Segundo Acot (1990), a importância deste fato é que pela primeira vez 
apareceu um conceito científico que permitiu integrar elementos dos reinos vegetal e animal. No entanto, Möbius ainda não constituiu um corpo conceitual suficiente que possibilitasse a prática biocenótica, mas contribuiu significativamente para os estudos de 1920 .

Outro ponto importante foi o começo dos estudos das relações de nutrição/predação animal-vegetal e das relações interespecíficas. Assim, avançaram os estudos no que, mais tarde, chamamos de "dinâmica das populações", ou seja, estudar e quantificar as variações de abundâncias dos organismos que compõem as biocenoses. Neste sentido, destacamos Charles Elton, em 1927, com a obra Animal Ecology, a qual leva em conta a importância numérica de certas populações e suas variações (ACOT, 1990). Aqui, se abre um caminho para a formulação matemática da ecologia, bastante difundida nos dias atuais. Lokta e Volterra foram os que, primeiramente, apresentaram trabalhos matemáticos sobre estas inter-relações, tentando relacionar as hipóteses matemáticas à realidade experimental. Logo após, G. F. Gause continuou estudos neste sentido e estabeleceu o "Princípio da exclusão competitiva". No entanto, este autor salienta que as espécies têm certo grau de seletividade, portanto, podem não corresponder fielmente às probabilidades estatísticas, necessitando das experiências em campo para confrontar com a realidade ecológica. Assim, em 1930, tornou-se operatório o termo biocenose.

Ainda neste período, podemos destacar a fitossociologia vegetal que começou a desenvolver seus trabalhos e confrontos, pois se tornava necessário estabelecer relação entre formações (fisionômicas) e associações (critérios que se tornavam gradualmente florísticos), tendo como nascimento a noção de grupamentos vegetais, descontinuidades vegetais. Assim, destacamos os trabalhos de Grisebach, Ramenky, Gleason, Curtis, Whittaker, Braun-Blanquet, entre outros. Neste contexto, o importante a destacar é o papel da fitossociologia na história da ecologia, a qual foi uma lenta ascensão dos ecólogos a uma concepção sintética das comunidades, na qual as inter-relações complexas existentes entre cada um dos seus elementos constituem um sistema estruturado, que convém avaliar (ACOT, 1990). Dessa forma, o progresso dessas concepções, na primeira metade do século, criou condições à edificação, no decorrer dos anos 1930, de uma teoria sintética da ecologia: a ecologia de ecossistemas.

Neste contexto foi que, em 1935, A. G. Tansley desenvolveu o conceito de ecossistema, tendo como ponto importante a integração dos fatores químicos e físicos entre o meio ambiente inorgânico e as comunidades. No entanto, Acot (1990) alerta que esta consideração dos fatores abióticos já foi mencionada por Humboldt e que ela representa o ponto central no pensamento ecológico. O progresso notável está na integração em um 
sistema único do meio ambiente abiótico e das comunidades. Ainda em 1939 eram poucos os trabalhos que tratavam destas abordagens, mas no ano de 1940 houve uma progressão nítida. Assim, podemos destacar os trabalhos de F. A. Forel, atuando em lagos com cadeias tróficas, e Chancey Juday introduzindo, pela primeira vez, conceitos da física para quantificar a energia de uma estrutura trófica da biocenose.

Foi a partir deste cenário histórico que Raymond Lindeman, em 1941, lançou as bases da Ecologia Moderna, introduzindo a noção de organismo autotrófico e relações entre os níveis tróficos. Assim, segundo Acot (1990, p. xx), Lindeman fez a ecologia progredir bastante ao sugerir ampliar a sua análise a qualquer ecossistema, afirmando que "as análises dos ciclos de relações tróficas indicam que uma comunidade biótica não pode ser claramente diferenciada de seu meio ambiente abiótico: a partir disso, o ecossistema deve ser considerado como a unidade ecológica fundamental" e que "o processo fundamental das relações tróficas é a transferência de energia de uma parte do ecossistema para a outra". Desse modo, seu trabalho permitiu avanços importantes para a ecologia como a termodinâmica do ser vivo, introduzida pelo físico Schrödinger em 1945, e a cibernética com Norbert Wiener. Neste momento, considero que a ecologia adquiriu um salto mais alto enquanto ciência integradora ao estabelecer diálogo entre fatores abióticos e bióticos, elaboração de teorias e experimentações do ambiente. Isso proporcionou aos pesquisadores a percepção das redes de entrelaçamento e a complexidade de fatores que estão envolvidos nas questões ecológicas e que estas estão relacionadas a processos e funcionamentos abertos extremamente interdependentes (autoecoprodutores) uns com os outros.

No entanto, o advento da segunda Guerra Mundial fez com que as produções nesta área freassem, voltando gradualmente a aumentar por volta de 1948, no entanto, ainda eram poucos os trabalhos diretamente centrados na teoria dos ecossistemas. Este cenário se modificou quando, em 1953, foi publicado "Fundamentals of Ecology", de E. P. Odum, o qual apresenta um resumo de teorias, conceitos e pesquisas em ecologia, de uma forma sistemática e didática. Assim, segundo Acot (1990), esta obra tem uma importância considerável em ecologia, pois será um dos livros básicos para o estudante de ecologia e ele diz ainda que não existe ecólogo contemporâneo que não tenha lido.

Segundo Acot (1990), neste momento o pensamento ecológico substitui um espaço ecológico dividido por um reunificado, nos quais os fatores bióticos e abióticos fazem parte de uma mesma realidade. Neste sentido, ele ainda nos alerta que toda mudança científica importante passa por uma mudança da maneira de ver o mundo, portanto, a teoria de 
ecossistemas induzirá ao desenvolvimento de uma ideologia ecologista sistêmica que transformará as representações sociais da relação natureza-sociedade.

Dessa forma, foi que em 1950 realizou-se o primeiro encontro nacional da história exclusivamente de ecologia (ACOT, 1990). Neste evento, ainda não apareceram trabalhos sobre a ecologia de ecossistemas, mas houve o apontamento para duas tendências: investimento em novos campos de estudo e desenvolvimento de uma ecologia microbiológica. Assim, destacamos as contribuições da termodinâmica e da cibernética à ecologia. Esta primeira traz a noção de "ordem, desordem e entropia" nos sistemas vivos e a cibernética vem lhe dar a coerência. A noção importante trazida por estas duas disciplinas é que o ecossistema possui mecanismos de equilibração (feedbacks negativo e positivo - auto-organização) e evolui para um estado climático, ali se mantendo em um equilíbrio dinâmico. Diante disso, segundo Acot (1990), em 1960, essas pesquisas conduziram à elaboração de modelos matemáticos de evolução dos ecossistemas, importante mecanismo para predizer os seus estados. Outro ponto importante é a analogia que Nobert Wiener (criador da cibernética) faz entre a informação e a entropia, mostrando as múltiplas possibilidades de utilizar a informática para o tratamento de modelos cibernéticos de ecossistemas.

Todos estes avanços teóricos do pensamento ecossistêmico constituem os grandes traços da história recente da ecologia (ACOT, 1990) e têm implicações diretas nas práticas desenvolvidas. Um exemplo disso são as práticas agrícolas, as quais vivem a contradição entre a dinâmica natural da vegetação e a artificialização das práticas culturais de cultivo que levam a dificuldades ecológicas e econômicas. Assim, a teoria de ecossistemas vem como uma estratégia de enfrentamento, uma vez que propõe pensar em grande escala os equilíbrios entre os sistemas. Outro exemplo são as populações selvagens exploradas, um problema difícil de resolver em razão da sua complexidade. No entanto, a teoria de ecossistemas vem com a estratégia de pensar na dinâmica das populações aliada ao pensamento ecossistêmico, constituindo a gestão de ecossistemas.

Neste contexto, Acot (1990) salienta que a característica sintética da teoria de ecossistemas e sua extensa aplicação nas práticas humanas levam os ecólogos a considerar a espécie humana como integrante da natureza. Assim, surge a ideia de Ecologia Humana, tendo como objeto a interface entre a natureza e a sociedade, em que o homem como espécie biológica também é marcado por sua cultura, e que, por conseguinte, transforma a natureza para as suas necessidades biológicas e sociais. Estas relações possuem especificidades que causam dificuldades, principalmente, metodológicas para os ecólogos. Portanto, é importante refletir sobre a história de suas concepções científicas e ideológicas. 
A história da ecologia humana saiu principalmente da geografia. Remontando os anos de 1822, vemos na obra "Geografia geral comparada", de Karl Ritter, referências aos efeitos da natureza sobre os povos, e entendemos que existe uma causalidade linear que submete o homem à natureza. Da mesma forma, em 1845, Humboldt também falava da influência da natureza sobre o homem. No entanto, foi com Ratzel, por volta de 1885, que conhecemos importantes contribuições para a gênese da ecologia humana. Para ele, já a evolução das sociedades está estreitamente ligada às condições do meio externo e à difusão dos traços culturais no espaço geográfico, sendo atravessadas pela necessidade de habitação e alimentação.

Neste sentido, para Acot (1990), foi somente em 1921 que ocorreu o nascimento da Ecologia Humana, no qual foi publicado um artigo de Ekblaw na revista "Ecology" sobre as relações ecológicas dos esquimós. Depois disso, alguns poucos trabalhos foram desenvolvidos, como de Forbes, em 1922, e de C. C. Adams, em 1935. Este último demonstra um interesse potencial da transferência dos conceitos da ecologia para a sociologia. Este laço teórico entre essas duas disciplinas aparecem nos trabalhos da escola de sociologia urbana de Chicago, como por exemplo, Roderick D. McKenzie e Robert Ezra Park. Nos seus trabalhos, os autores fazem aproximações dos conceitos da ecologia à sociologia com "jogo de palavras", cientificamente fraco, e consideram, por exemplo, a cidade como produto da natureza, embora artificial. Segundo Acot (1990), esse "erro" levou a ecologia humana da época a ser considerada cientificamente pobre e não sem muita credibilidade.

Dessa forma, segundo Acot (1990), no período entre as duas guerras, as publicações científicas na área de ecologia humana ainda não constituíam um todo coerente, mas, sim, a expressão de tentativas díspares e artificiais de integrar os conhecimentos das duas ciências. O autor ainda salienta que o desenvolvimento da teoria de ecossistemas não ajudará muito neste sentido, visto que normalmente as abordagens são simplificadoras, não levando em conta a dimensão cultural nas relações entre a sociedade e o ambiente.

Acot (1990) lança a seguinte frase: "Parte integrante da natureza, os homens tendem, no entanto, a se emancipar dela, transformando-a", a fim de discutir as contradições existentes nesta relação. Ele fala que estas tensões aparecem quando pensamos em uma natureza original nostálgica e antiga destruída desde o século XVI pelo pensamento humano e no século XX pelo poder degradante dos sistemas econômicos que se acreditam possuidores da natureza. Segundo Lago e Pádua (1985), foi com o advento da Revolução Industrial, nos séculos XVIII e XIX, que houve um impacto acelerado do homem no meio ambiente. No entanto, as preocupações com este fato somente aumentaram significativamente no século $\mathrm{XX}$, refletindo 
em um aumento da preocupação acadêmica sobre o assunto. De acordo com os autores, os pensadores da época apostavam nas possibilidades da industrialização e não possuíam até então uma preocupação com os limites naturais.

Em um contexto histórico, podemos perceber os primeiros atos de proteção à natureza, meados de 1669, como uma proteção de gerentes, ou seja, age-se como um protecionista, cuidando da natureza, das riquezas do país que ele mesmo administra. Dessa forma, segundo Acot (1990), essas iniciativas seriam mais uma máscara de uma dominação lucrativa, assim como os numerosos jardins botânicos criados na época. No entanto, nos séculos XVII e XVIII, ligados à agronomia, surgia a preocupação com a preservação dos equilíbrios naturais, como, por exemplo, o que se chamou de "primeira revolução verde".

Já no século XIX, a grande questão filosófica que aparece nos debates científicos é a da unidade material do mundo, a qual se encontra com muita dificuldade, pois as opções são salvar a especificidade humana, instigando dualismos antigos, ou incluir os homens subordinando-os dessa forma às leis da biologia. Neste sentido, um ponto que permite pensar essa "unidade material do mundo" são as ideias de organicismo, as quais aparecem pela primeira vez em 1901 com Clements. No organicismo de Clements, há uma estrutura e um desenvolvimento específico e repetitivo nas comunidades vegetais e o entendimento de que conceitos operatórios para pensar as plantas individuais são transferíveis para os conjuntos vegetais (ACOT, 1990). No entanto, estas concepções não são aceitas por todos os pesquisadores, gerando uma polêmica que durou quase 40 anos. Essa concepção também atingiu o estabelecimento da ecologia humana, mesmo que ilegítimo. Segundo Acot (1990), o ponto de vista organicista é estéril quando é adotado para considerar as comunidades humanas, ou seja, quando a abordagem cultural é investida pelo procedimento naturalista.

Cabe ressaltar que o pensamento biogeográfico (responsável pelo desenvolvimento de muitos conceitos da ecologia) não aborda estas questões, ignorando em suas pesquisas fenômenos que suscitam uma prática social em grande escala no campo dos equilíbrios naturais (ACOT, 1990). Segundo Acot (1990), seria preciso esperar os anos de 1920 para constatar o ressurgimento desta problemática, modernizada e, somente em 1940, assistir a sua integração harmoniosa num pensamento ecológico. A partir disso, constituiu-se uma transformação sistêmica do biologismo social, que representou um dos traços característicos da ideologia ecologista dos anos 1970 (ACOT, 1990).

Neste contexto, entre o fim do século XIX e década de 60, como consequência do imenso avanço internacional da produção industrial e da degradação ambiental, observado após a Segunda Guerra Mundial (LAGO; PÁDUA, 1985), surgem, como enfrentamento a 
esses problemas, três atitudes: a conservação da natureza, o biologismo social e a sacralização objetiva da natureza mítica. Essas se completam no que hoje chamamos de ecologismo. Segundo Lago e Pádua (1985), o lançamento, em 1962, do livro "Primavera Silenciosa", de Rachel Carson, denunciando os problemas causados pelo uso do DDT (sigla de diclorodifeniltricloroetano), primeiro pesticida largamente utilizado após a Segunda Guerra Mundial, e outros agrotóxicos, provocou preocupação na opinião pública americana, ocasionando um avanço no pensamento socioecológico.

Em relação à conservação da natureza, as primeiras medidas que foram tomadas, já por volta de 1872, nos Estados Unidos, e em 1963, na França, foi a criação de parques de preservação da natureza "original", que funcionavam como verdadeiros "santuários" onde se encerravam relíquias. Também já começaram os encontros internacionais para discutir o tema, a criação de comitês e o firmamento de acordos para a proteção da natureza. Na década de 40, foi criada a União Internacional para a Conservação da Natureza e de seus recursos (UICN), com o objetivo de incentivar a preocupação com os problemas ambientais (LAGO; PÁDUA, 1985). No Brasil, ocorreu, em 1934, a 1ª Conferência Brasileira de Proteção à Natureza e, no ano de 1958, foi estabelecida a Fundação Brasileira para a Conservação da Natureza.

Ao longo do tempo, muitos trabalhos e encontros de discussões sobre o tema foram realizados e, em 1968, os problemas do meio ambiente chegam à Organização das Nações Unidas (ONU), na qual a ideia de conservação pela criação de santuários é abandonada por uma concepção ao mesmo tempo mais complexa e mais dinâmica. Em 1972, aconteceu a Conferência de Estocolmo, onde foram lançadas as bases de uma legislação internacional do meio ambiente (ACOT, 1990).

O biologismo social seria a aplicação de conceitos particularmente da biologia às sociedades humanas. Neste contexto, podemos citar os trabalhos de Jean-Marie Pelt, em 1977, Joël de Rosnay, em 1979, e Brice Lalonde, em 1981. No entanto, os ecólogos contemporâneos não se detêm a meras aproximações ingênuas como no passado, usa-se uma abordagem sistêmica do mundo, na qual todos os elementos, inclusive as sociedades humanas, interagem numa gigantesca rede de relações (ACOT, 1990). Assim, para os ecólogos, a solução aos problemas energéticos seria adotar tecnologias mais "suaves" de produção de energia (ACOT, 1990). Ainda conforme Acot (1990), no fim dos anos 1970, o ecologismo tornava-se uma visão de mundo e um modo de vida, mais do que uma corrente mais ou menos organizada de defesa da natureza. Dessa forma, a partir do primeiro relatório do Clube de Roma, em 1972, os ecólogos teorizavam uma rejeição aos modos de vida tradicionais nas sociedades capitalistas adiantadas. Segundo Acot (1990), o conjunto de 
ecólogos desenha uma imagem de uma sociedade participativa, convivível, fraterna, caridosa, solidária, descentralizada e com perfil de baixo consumo. Considerando Lago e Pádua (1985), apenas uma mudança nas estruturas econômicas, sociais e culturais pode encaminhar uma solução, visto que o modelo dominante não é apenas ecologicamente insustentável como também socialmente injusto. Diante disso, podemos perceber uma visão "romântica" dos ecólogos, em que a essência das ideias ecologistas é ser um pensamento de amor e de aliança, que leva ao que Acot (1990) chama de "retorno ao sagrado". Segundo Acot (1990), seria um retorno a uma aliança muito antiga, mítica e sagrada, da qual somos culpados pela violação coletiva da natureza virgem, irremediavelmente maculada pelas consequências de nossa cobiça e utilitarismo. Aqui, para os ecólogos, a natureza está no terreno dos valores, ou seja, é valor supremo.

No entanto, existe uma corrente de ideias totalmente oposta à concepção conservadora, biologista e sacralizante que surge no decorrer do século $\mathrm{XX}$, que é progressista, manipuladora e materialista, herdeira de um pensamento cartesiano (ACOT, 1990). Nesta concepção, a ideia é atacar as causas concretas da degradação do ambiente ao invés de colocá-la como consequência fatal da ação do homem. Com o ecólogo marxista Guy Bilat (apud ACOT, 1973), podemos compreender claramente a essência do pensamento desta corrente em relação ao produtivismo: "a acumulação dos conhecimentos e o desenvolvimento das ciências e das técnicas devem permitir ao homem o domínio cada vez mais consciente sobre a natureza". Dessa forma, para esses ecólogos, a solução para a crise atual do meio ambiente seria a execução de medidas de gestão dos ecossistemas. Assim, Acot (1990) diz que a história da ecologia e o ecologismo nos leva a refletir sobre a hipótese da existência de uma ligação entre a emergência de relações novas entre os homens e a natureza e a de novas relações entre os próprios homens.

Neste contexto, podemos perceber que ao longo de História, muitas abordagens, conceitos e concepções sobre ecologia foram emergindo, algumas destas influenciadas por questões políticas de transformação social. Assim, segundo Odum (2001), antes da década de 1970, a ecologia estava muito ligada à biologia, e era geralmente encontrada apenas nos currículos das ciências biológicas. No entanto, nas últimas décadas, a ecologia emergiu como uma disciplina integradora, envolvendo processos naturais (físicos e químicos), biológicos (organismos, populações e comunidades) e sociais. Segundo Lago e Pádua (1985), a ecologia hoje não é usada apenas para designar uma disciplina científica, mas para identificar um amplo e variado movimento social, tornando-se um dos temas mais debatidos e que interessa cada vez um maior número de pessoas. 
Assim, a ecologia, por se apresentar como uma disciplina que integra diversos conhecimentos, gera certa dificuldade na definição do seu âmbito de estudo. Lago e Pádua (1985) propuseram que o pensamento ecológico se dividiu em grandes áreas do conhecimento: Ecologia Natural, Ecologia Social, Conservacionismo e Ecologismo. Como observamos, em pouco mais de um século a ecologia saiu do campo restrito da biologia, penetrou no espaço das ciências sociais e passou a denominar um amplo movimento social organizado em torno da questão da proteção ambiental, gerando confusão pelos discursos de natureza bastante diversa (LAGO; PÁDUA, 1985). Portanto, hoje, devido a isso, a ecologia permeia diversos campos científicos, sendo que esta disciplina nas universidades é encontrada como obrigatória não somente nas graduações de Ciências Biológicas, como também, por exemplo, em cursos de Licenciatura em História, Educação Física, e cursos bacharelados como Engenharia Florestal, Zootecnia, Meteorologia, entre outros.

No entanto, Lago e Pádua (1985) alertam que estas subdivisões deste campo do conhecimento não são diferentes e isoladas, mas são distintas abordagens de uma mesma realidade e se complementam mutuamente. Portanto, os autores salientam que para ter uma visão mais complexa do campo da ecologia é importante ter uma perspectiva global, examinando-se as especificidades (parte) e a evolução de cada área em função da sua relação com o conjunto (todo).

\section{A Ecologia Emergente}

Diante do exposto, podemos perceber que a história da ecologia enquanto ciência se constituiu buscando alguns dos seus resultados e métodos em numerosas áreas. Portanto, essas transferências conceituais e metodológicas, por vezes, podem trazer dificuldades ao reconstruir sua história, uma vez que no passado já foi levantada a complexidade de sua legitimidade e fecundidade enquanto ciência e, hoje, o uso pelas ciências sociais de conceitos próprios à ciência ecologia (ACOT, 1990). No entanto, a sua história torna-a uma área do conhecimento integradora, envolvendo processos naturais (físicos e químicos), biológicos (organismos, populações e comunidades) e sociais. Morin (2007) também destaca esta característica da ecologia dizendo que

a ecologia que parte dos ecossistemas e assume a biosfera como objeto e que é, evidentemente, uma ciência polidisciplinar, pois o ecologista não retém em sua mente todo o saber de botânicos, zoólogos, microbiólogos e geólogos, mas se ocupa com regulações, apelando a diferentes especialistas (MORIN, 2007, p.33). 
Morin (2006) mostra que a segunda revolução científica do século XX contribui com a ligação, contextualização e globalização dos saberes até então fragmentados e compartimentados. Dentre esses, encontramos a Ecologia, a qual, segundo o autor, é uma poli ou transdisciplina, que tem por objeto não só um setor ou uma parcela, mas um sistema complexo, onde as partes e o todo produzem e se organizam entre si.

Neste sentido, com base no pensamento complexo, entendemos que a ciência ecológica emergente requer uma visão de mundo e das inter-relações complexas, nas quais todos os seus componentes bióticos e abióticos se entrelaçam em uma rede/teia de interretroações complementares e antagônicas em um todo dinâmico. E esse cenário pode ser visualizado nos mais diferentes níveis de organização, ou seja, desde o nível macro do cosmos até o nível dos indivíduos, células e átomos. No entanto, aqui, cabe ressaltar que não estamos falando da ideia de superorganismo, bastante discutida em ecologia, mas propomos que há a necessidade de um pensamento ecológico organizacional. Portanto, Morin (2015a) diz que a ciência ecologia não se detém somente na ação das características físicas e climatológicas do ambiente nas comunidades bióticas, tão pouco somente das relações ecológicas entre os organismos que constituem estas comunidades, mas é "a ciência das interações combinatórias/organizadoras entre os componentes físicos e vivos dos ecossistemas" (MORIN, 2015a, p.33).

Assim, a ecologia, fazendo uso dos conhecimentos disciplinares das mais variadas áreas do conhecimento (biologia, química, física, geografia, matemática e estatística, entre outras) em suas ordens e desordens, estuda-os, relaciona-os e integra-os, propondo entendimentos ecológicos, superando as visões fragmentadas e preocupando-se com as regulações dos fenômenos, ou seja, com dinamicidade da ordem organizacional da vida. $\mathrm{Na}$ ciência ecológica, podemos perceber a dialógica do tetragrama ordem-desordem-interaçãoorganização, proposto por Morin (2010), possibilitando entendimentos complexos das relações com o mundo, em quaisquer níveis de organização.

Como percebemos na evolução histórica dos conhecimentos ecológicos e "préecológicos", tanto nos estudos com os organismos, as populações e, até mesmo, as comunidades, os pesquisadores se preocuparam, em um primeiro momento, em buscar os padrões individuais estáticos (ordem) para, posteriormente, com Clements, atentarem às as dinâmicas ao longo do tempo, observando, assim, a vulnerabilidade e instabilidade (desordem) destes. Estas concepções de organização da vida, quando observadas isoladamente, podem, por vezes, parecer contraditórias e excludentes, o que acaba gerando dificuldades em estabelecer mecanismos de regulações dos processos ecológicos. $\mathrm{Na}$ ecologia 
emergente, precisamos organizar a compreensão por meio da dialógica entre os diferentes conhecimentos, superando a dualidade dos fenômenos, e reconhecer uma terceira dimensão organizacional da vida, a qual Morin (2015a) chama de eco-organização.

Nesta proposição, ressaltamos mais uma vez (como na própria história da ecologia) a importância do conceito de ecossistema, enquanto unidade fundamental da noção de ecoorganização. No entanto, lembramos que este conceito precisa ser ampliado, como uma unidade organizadora, ou seja, um sistema ativo concomitantemente produzido, constituído (ordem) e dilacerado (desordem) por suas interações internas, as quais produzem uma organização complexa (MORIN, 2015a). No olhar ecossistêmico, podemos observar a unidade na diversidade, um sistema de incontáveis unidades, por si só já complexas, os organismos, na diversidade de formas, espécies, condições geomorfológicas, climatológicas e ambientais. Tudo isso ainda em constantes interações solidárias (simbioses, associações, mutualismos) e conflituosas (predação, competição, egocentrismos). E é neste aparente caos de relações extremas que se estabelece uma organização complexa tão regulada, na qual as interações complementares e antagônicas não só coexistem, mas estão ligadas pela necessidade (MORIN, 2015a).

Portanto, Morin (2015a p. 34) diz que a "eco-organização é inseparável da constituição, da manutenção e do desenvolvimento da diversidade biológica". Assim, os conceitos ecológicos são complexificados no sentido de serem considerados processos autoorganizados e eco-organizados. Nesta rede complexa de interações, precisamos pensar, ainda, a ecologia inseparável do antropossocial, uma vez que o desenvolvimento da sociedade sempre esteve ligado à natureza, da mesma forma que a natureza está em estreita relação com as sociedades. Portanto, Morin alerta que

temos de conceber de modo recorrente o duplo envolvimento da sociologia pela ecologia e da ecologia pela sociologia, duplo envolvimento necessariamente aberto, em que nenhuma das duas ciências encerra a outra, mas no qual ambas estão no movimento de relação rotativa. (MORIN, 2015a, p. 95)

Assim, a ecologia emergente decorre da percepção da complexidade sobre a existência do ser vivo, sobre os conceitos já estabelecidos em outras áreas do conhecimento, bem como as relações ecológicas que se estabelecem nos ecossistemas. O pensamento ecológico necessita reconhecer que as relações cíclicas (ex.: ciclagem de nutrientes, ciclos ecológicos) e em cadeia (ex.: cadeias tróficas) precisam ser reunificadas no conceito de anel (ecoorganizador) (MORIN, 2015a). Mais do que isso, na complexidade das relações ecológicas da vida, temos múltiplos e incontáveis anéis (eco-organizadores), "constituídos de grandes 
ciclos, cadeias e anéis formados por miríades de minianéis inter-retroativos" (MORIN, 2015a, p. 45). Além do mais,

cada momento de um ciclo constitui, ao mesmo tempo, o momento de um ou vários outros, no qual desempenha papéis diferentes ou mesmo opostos. Mas todos se inserem num grande policircuito de degenerescência/regeneração, desorganização/reorganização, do qual são os coprodutores e os coproduzidos. (MORIN, 2015a, p. 45)

Portanto, na ecologia emergente, precisamos falar de relações complexas, em que cada anel forma uma parte integrante e relacional dos plurianéis do grande plurianel que constitui a própria eco-organização. Este entendimento nos permite um olhar ampliado da infinidade das relações que mantêm a vida, compreendendo mais precisamente suas interações, regulações e comportamentos. Assim, o olhar ecológico emergente é autoecorrelacional, ou seja, necessita das autodimensões da vida (organismos, espécies etc.) como também das ecodimensões (ecossistemas, biosfera etc.), considerando que tais dimensões estão entrelaçadas de tal modo que são, ao mesmo tempo, coconstitutivas e ecoconstitutivas (MORIN, 2015a).

Considerando isso, para desenvolvermos tais concepções em uma ecologia emergente, necessitamos, como alerta Morin (2015a), de uma reforma do pensamento, visto que "a complexidade do princípio ecológico degrada-se em uma ecologia mental simplificadora, redutora, cartesiana ou maquineísta" (MORIN, 2015a p. 109). Portanto, é necessário um pensamento ecologizado que considere a multidimensionalidade e complexidade dos fenômenos em constante movimento, ou seja, a dinâmica policêntrica autoeco-organizacional da vida.

\section{Ciência ecológica: Da historicidade à concepção emergente}

Diante das considerações históricas, podemos compreender a evolução da ciência ecológica, na qual cada acontecimento e conhecimento gerado integram, produzem e são produzidos a cada momento histórico, formando uma espiral recursivamente autoalimentada. Desta compreensão, chegamos à configuração da espiral apresentada na figura 1, na qual podemos observar que na sua origem, a ecologia era basicamente feita na observação dos fenômenos, ou seja, os organismos no ambiente, e o estabelecimento de relações causais mais lineares baseadas no providencialismo e finalismo. Já no início do século XIX, com Humboldt, começamos uma fase mais descritiva da ecologia, uma vez que era preciso conhecer as espécies, as características do ambiente e como estas variavam nos diferentes locais para, depois, poder estabelecer as inter-relações ecológicas. Isso culminou, em 1866, 
com a denominação do próprio conceito de "ecologia" enquanto campo do conhecimento a ser consolidado.

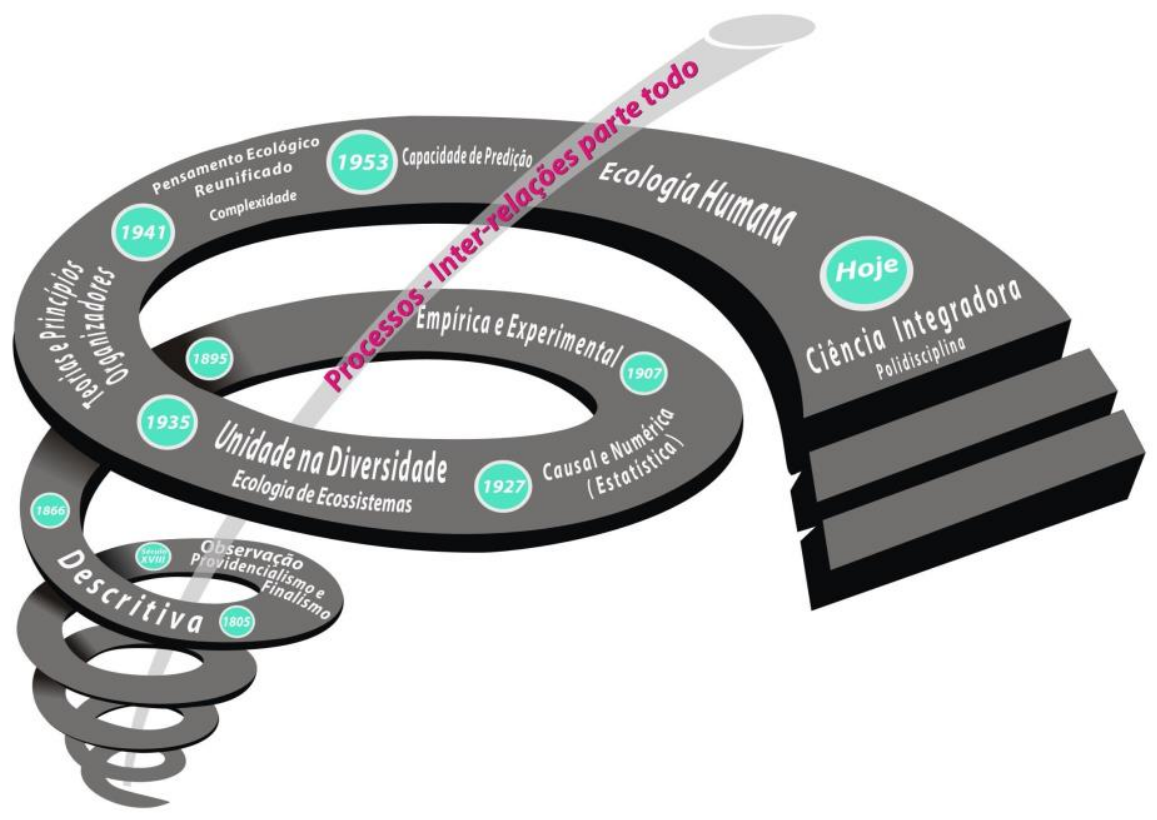

Figura 1 - Representação da evolução histórica da ciência ecológica.

Fonte: Construção do autor.

Assim, com os avanços nas pesquisas, principalmente depois dos estudos de Warming, partimos para uma ecologia mais empírica e experimental. Neste momento, vemos metodologias e instrumentos de pesquisa sendo desenvolvidos e utilizados em campo e laboratório, como pudemos perceber nas contribuições de Clements.

Esta historicidade possibilitou estabelecer causalidades nos fenômenos experimentados, e a quantificação ganhou status, no qual vemos fortemente os modelos matemáticos e a estatística promovendo generalizações das relações ecológicas. No entanto, foi a partir de 1935, com o aparecimento do conceito de ecossistema, que notamos um progresso, uma vez que houve a integração em um sistema único (o ecossistema - unidade) do ambiente abiótico e das comunidades (diversidade). Assim, promoveu o desenvolvimento de diversas pesquisas nos mais variados ecossistemas, o que possibilitou a visualização de padrões de distribuição de espécies, mecanismos de regulação, entre outros, levando a formulação de teorias e princípios ecológicos organizadores. A partir disso, Lindeman lançou as bases para a Ecologia Moderna, considerando o ecossistema como unidade ecológica fundamental, na qual poderiam ser observadas as relações tróficas e a transferência de energia, inspirando outros pesquisadores, como a termodinâmica. Portanto, aqui, 
consideramos a percepção da ecologia como ciência integradora, uma vez que o pensamento ecológico passou a ser reunificado, adquirindo, assim, complexidade.

Todos esses avanços levam a ecologia a ter a capacidade de fazer predições dos fenômenos ecológicos, propiciando os mais diferentes interesses, tanto ambientais quanto econômicos. Assim, esse pensamento sistêmico leva a transformações sociais da relação natureza-sociedade e, somente aqui, começamos a ver uma valorização da ecologia humana, ou seja, o homem começa a fazer parte deste ecossistema. Desta forma, aumentam as preocupações com a relação do homem com o ambiente, aproximando a ecologia também das ciências sociais e gerando diversos posicionamentos sobre a natureza desta relação, como já mencionado no texto.

\section{Considerações Finais}

A ciência ecológica é muito mais do que uma disciplina científica: é uma ciência/consciência planetária, na medida em que envolve todas as dimensões da vida e das relações com o mundo que nos cerca. Portanto, comporta em sua essência um pensamento ecologizado que introduz um olhar, uma dimensão auto-eco-organizadora da descrição, explicação e interpretação de qualquer fenômeno.

Neste sentido, vemos emergir uma ciência nova integradora que considera o seu objeto de estudo mergulhado no contexto, descrevendo-o e concebendo-o nas inter-retroações com os mais diferentes componentes, os quais, por sua vez, se relacionam com conceitos das diversas disciplinas clássicas (físicas, biológicas, antropossociais etc.), complexificando-as (MORIN, 2015a). Além disso, permite a comunicação entre ciência, natureza, cultura e consciência, na medida em que introduz a reflexão da relação homem/natureza na sua multidimensionalidade e atualidade.

Esta ciência integradora, não somente ligada às ciências naturais, como na sua origem, é também íntima das ciências sociais, sendo considerada e discutida nos mais diferentes âmbitos da nossa sociedade. Além disso, por ter a contribuição das mais diversas áreas do conhecimento na sua historicidade e, até mesmo, por seus próprios pressupostos organizadores, consideramos a ecologia uma polidisciplina. E como pudemos perceber ao longo de todo o seu progresso enquanto ciência, temos, como principal eixo organizador, o reconhecimento dos processos como inter-relações entre parte e todo. Cabe, aqui, salientar que nesta espiral do tempo construída, consideramos que cada ponto ao longo da história não termina em si, mas está sempre se retroalimentando ao longo do tempo, portanto, todos os 
acontecimentos são recursivamente interdependentes e policêntricos/acêntricos (MORIN, 2015a).

No entanto, para pensarmos em uma ecologia emergente, precisamos ampliar esta espiral e observar um emaranhado/enovelamento de múltiplos e infinitos plurianéis em movimento e de modo policêntricos/acêntricos, em que todos os níveis de organização (macro, micro, nano, biológico, geofísico, químico, funcional etc.) estão superpostos, mutuamente interligados, contribuindo para a autoeco-organização deste grande plurianel. A figura 2 apresenta uma tentativa de representação deste plurianel.

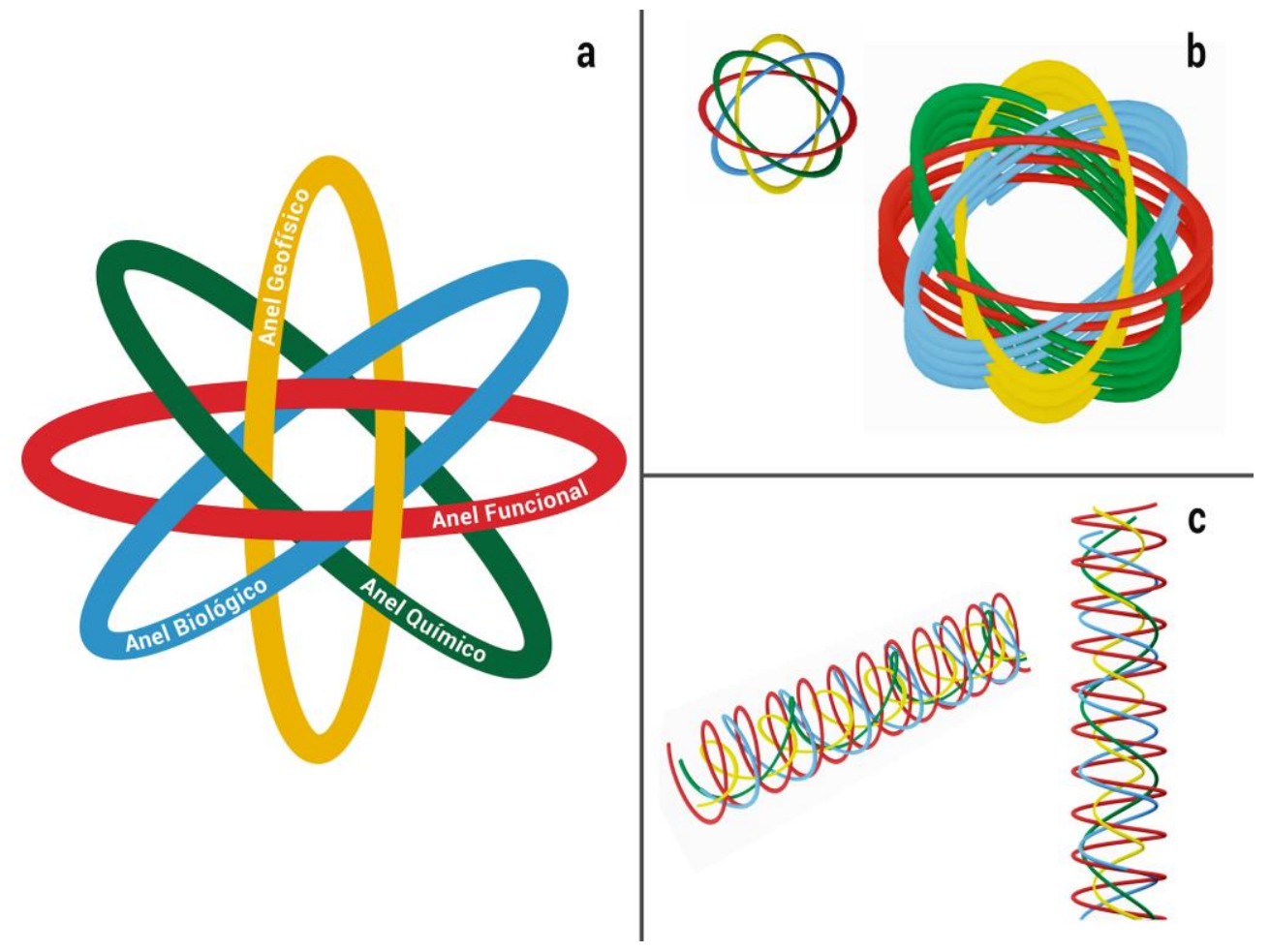

Figura 2 - Representação de uma ecologia emergente.

Fonte: Construção do autor.

A representação da figura 2a mostra simplificadamente alguns dos infinitos plurianéis entrelaçados, com seus inúmeros pontos de interações, os quais estão sempre em movimento, portanto mudando constantemente de posição. Nesta primeira imagem temos um olhar frontal dos anéis, já em $2 b$ mostramos outro ângulo para que possamos compreender que cada anel se configura como uma espiral. E na tentativa de ilustrarmos o movimento dinâmico destas miríades de plurianéis (em espiral), representamos em 2c este movimento em perspectiva. 
$\mathrm{Na}$ configuração de uma ecologia emergente, vemos os múltiplos circuitos que compõem e mantêm os fenômenos da vida entrelaçados de modo que não existem centros reguladores, mas um movimento dinâmico de inter-retroações que conectam/desconectam, geradores/degeneradores dos acontecimentos, de forma caótica e, ao mesmo tempo, autoecoorganizada.

Levando essa concepção para o desenvolvimento da ciência ecológica científica, vemos todos os acontecimentos históricos (finalistas, providencialistas, descritivos, reducionistas, ecossistêmicos, complexos), como também a contribuição das diversas disciplinas clássicas, como co-produtores de uma ciência ecológica integradora, de forma que cada contribuição integra um elo à complexidade das interações.

\section{Referências}

ACOT, P. História da Ecologia. Trad. Carlota Gomes. Rio de Janeiro:Campus, 1990.

ADAMS, C. C. The Postglacial Dispersal of the North American Biota. Biological Bulletin, v. 9, n. 1, p. 53-71, 1905.

BODENHEIMER, F. Shimon. Aristotle, the Father of Animal Ecology, Homenaje a MillasValicrosa, v. I, Barcelona, 1954.

EGERTON, F. N. A Bibliographical Guide to the History of General Ecology and Population Ecology. History of Science. XV, 1976.

LAGO, A.; PÁDUA, J. A. O que é Ecologia? São Paulo: Brasiliense, 1985.

MORIN, E. A cabeça bem-feita: repensar a reforma, reformar o pensamento. $12^{\circ}$ ed. Rio de Janeiro: Bertrand Brasil, 2006.

MORIN, E. Ciência com Consciência. 13º ed. Rio de Janeiro: Bertrand Brasil, 2010.

MORIN, E. O método 2: a vida da vida. $5^{\text {a }}$ ed. Porto Alegre: Sulina, 2015a.

MORIN, E. O método 3: conhecimento do conhecimento. $5^{\mathrm{a}}$ ed. Porto Alegre: Sulina, 215b.

ODUM, E. P. Fundamentos de Ecologia. Rio de Janeiro: Guanabara Koogan, 2001.

PRESTES, M. E. B.; OLIVEIRA, P.; JENSEN, G. M. As origens da classificação de plantas de Carl von Linné no ensino de biologia. Filosofia e História da Biologia, v. 4, p. 101-137, 2009.

ROSA, C. A. P. História da Ciência: O Pensamento Científico e a Ciência no Século XIX, v. II, Tomo II, 2. ed. Brasília: FUNAG, 2012.

SHELFORD, V. E. Preliminary note on the distribution of the tiger beetles (cicindela) and its relation to plant succession. Biological Bulletin. v. 14, n.1, 1907. 